\title{
Radiosensitizing effects of melatonin on radiation induced chromosomal aberration in G2-lymphocytes of breast cancer patients
}

\author{
E. Samei' ${ }^{1}$ H. Mozdarani2 ${ }^{*}$, F. Samiei ${ }^{3}$, G.R. Javadi ${ }^{1}$ \\ ${ }^{1}$ Department of Biology, Science and Research Branch, Islamic Azad University, Tehran, Iran. \\ ${ }^{2}$ Department of Medical Genetics, Faculty of Medical Sciences, Tarbiat Modares University, Tehran, Iran. \\ ${ }^{3}$ Department of Radiation Oncology, Cancer Institute, Tehran University of Medical Sciences, Tehran, Iran.
}

\section{- Original article}

\section{*Corresponding authors: \\ Prof. Hossein Mozdarani, Ph.D., E-mail:}

mozdarah@modares.ac.ir

Revised: August 2019

Accepted: September 2019

Int. J. Radiat. Res., October 2020; 18(4): $657-662$

DOI: 10.18869 /acadpub.ijrr.18.4.657

\begin{abstract}
Background: Radiotherapy is regarded as a standard treatment modality in breast cancer (BC). Radiation causes cellular damage both in cancer and normal cells by inducing DNA-damage and chromosomal aberrations (CA). Different agents were used for ameliorating effects of radiation, mainly antioxidants such as melatonin. Melatonin shows oncostatic properties on human BC. The aim of this study was to evaluate the modulating effect of melatonin on radiation induced CA in cells irradiated at $\mathrm{G} 2$ phase of the cell cycle. Materials and methods: G2 assay was applied on whole peripheral blood lymphocytes received from $10 \mathrm{BC}$ patients and 5 normal controls. Blood culture was initiated in complete culture medium. Four $\mathrm{h}$ prior to harvesting, cells were irradiated with $1 \mathrm{~Gy}$ gamma rays. Pretreatment of samples with melatonin was done $3 \mathrm{~h}$ before irradiation. After metaphase preparation and slide making, slides were stained in Giemsa. Hundred well spread metaphases were scored for the presence of chromatid type aberrations with a microscope at a magnification of $\times 1000$. Result: Results indicated a high and significant frequency of CA both in lymphocytes of normal and breast cancer patient after irradiation; however, the frequency was much more in lymphocytes from BC patients. Pretreatment of samples with melatonin led to a considerable increase in the frequency of aberrations especially in lymphocytes of BC patient. Conclusion: Results showed that despite having antioxidant property, melatonin led to enhanced frequency of radiation induced $C A$ in lymphocytes of $B C$ patients.
\end{abstract}

Keywords: Melatonin, breast cancer, chromosomal aberration, radiation therapy, G2 assay.

\section{INTRODUCTION}

Breast cancer is one of the most common neoplasia occurring in women mainly in developed countries that ranks as the fifth cause of death from all cancer (1). Breast cancer risk factors includes gender and age, family history, genetics, hormone therapy, exposure to ionizing radiation, dietary habits, obesity and alcohol and tobacco consumption as well as circadian disruption (2). Radiotherapy is one of the most common treatments for breast cancer. About
$80 \%$ of patients with $\mathrm{BC}$ receive $\mathrm{RT}$.

Radiation causes DNA damage directly or indirectly through ROS formation. The creation of ROS generates not only DNA strand breakages but also might act as a signaling event leading to the release of cytokines or epigenetic changes or trigger DNA repair machine (3). Ionizing radiation can cause cell cycle arrest which allows time for DNA repair and prevents the progression of damaged cells from the G2 phase into mitosis (4). Oxidative stress as ROS is involved in the etiology of many diseases 
including cancer (5). Unfortunately radio sensitivity of normal tissues contiguous to the tumor limits therapeutic benefit. Some of the patients show different degrees of mild to acute reactions.

Antioxidants are compounds, which combat the free radicals produced during radiation therapy. Antioxidants protect cells against development of cancer (5). Therefore, it seems logical to use antioxidant adjuvants to reduce radiotherapy toxicity (6).

Melatonin has been shown to have radio protective and anticancer effects. Antioxidant properties of melatonin based on free radical scavenging activity have been established in various experimental models (7). Melatonin ( $\mathrm{N}$ - acetyl -5 methoxy tryptamin) is an indoleamin secreted mainly by the pineal gland during the dark hours at night. Numerous studies have been performed to evaluate the oncostatic properties of melatonin against different neoplasias (8). Experimental studies carried out in rodents have shown that melatonin prevents the promotion and growth of mammary tumors (9-12). Also melatonin as an adjuvant therapy, conserves against the side effects of chemotherapeutic drugs (13). Disruption of nocturnal melatonin secretion is a risk factor for breast cancer (14). Cohen et al. (1978) proposed that decrease in melatonin levels might promote the development of breast cancer in human. Melatonin have properties of antioxidant reduces the side effects of radiotherapy (15) by scavenging ROS and reactive nitrogen species (16). The role of melatonin is to excite the expression of anti-oxidative enzyme (17) and deducting the expression of pro-oxidative enzymes (18).

Melatonin acts in different pathways involved in cancer treatment including, cell cycle regulation, differentiation, telomerase inhibition, apoptosis, metastasis, prevention of circadian disruption, and other related antioxidant properties (15). Although, other reports have also shown radiosentisizing effect of melatonin (19).

Melatonin pertains to the antioxidant group of radioprotectors (20). Melatonin may postpone the inhibition of the repair enzymes, hence allowing the repair of induced damage and the use of higher doses of radiation may supply better therapeutic value (20). Experimental research established the protective effect of melatonin against the genetic damage in blood, bone marrow and mortal effect of whole body radiation in mice (21).

Because of the controversies over the effect of melatonin, the aim of this research was to examine the effect of melatonin on $G_{2}$ lymphocytes of breast cancer patients and normal healthy individuals after irradiation to gamma rays.

\section{MATERIALS AND METHODS}

\section{Study subjects}

Whole blood sample was collected from 10 breast cancer patients with the mean age of $53.3 \pm 10.3$ (age range 37-78) and 5 healthy normal individuals with mean age of $39.6 \pm 11.6$ (aged 28-63) in heparinized tubes. The research was authorized by the institutional ethical committee. All donors gave their informed written consent and completed a written questionnaire to give information related to their personal life style including dietary habits, medical history and exposure to chemical and physical agents. Hence, to limit confounding factors, all samples were scrutinized to exclude former radiation exposure, antibiotic therapy and virus infection at least one month prior to sampling. Patients with breast cancer were not under chemo or radiotherapy treatment and all were diagnosed as new cases.

\section{Blood culture, melatonin treatment and irradiation}

Each sample from patient or healthy normal individual was divided into four parts: one part left without any treatment (Control, C), the second part was treated with melatonin alone $(\mathrm{M})$, third part was irradiated alone (R), and the forth one received melatonin $3 \mathrm{~h}$ before radiation $(\mathrm{R}+\mathrm{M})$. To each culture $0.4 \mathrm{ml}$ blood was added to $3 \mathrm{ml}$ RPMI-1640 Medium, supplemented with $15 \%$ fetal bovine serum, 1\% L-glutamine and antibiotics (penicillin $100 \mathrm{iu} / \mathrm{ml}$ and streptomycin $100 \mu \mathrm{g} / \mathrm{ml}$ ) (all reagents from

Int. J. Radiat. Res., Vol. 18 No. 4, October 2020 
Gibco BRL).

The lymphocytes were stimulated to divide with $1 \%$ phytohemagglutinin (PHA)(Sigma). Whole blood cultures were incubated at $37^{\circ} \mathrm{C}$, sixty-six hours later, melatonin (Chemidarou pharmaceutical co, Tehran, Iran) was added at a final concentration of $25 \mu \mathrm{g} / \mathrm{ml}$ to some samples. After 3 hours culture vessels were exposed to 1 Gy gamma rays generated from a ${ }^{60} \mathrm{Co}$ source
(ACEL, Canada) at a dose rate of 85 cGy / min. Slides were dried and stained in 4\% Giemsa for $10 \mathrm{~min}$. Chromatid breaks were scored and analyzed in well spread metaphase cells under $\times 100$ oil immersion light microscope. 100 cells were scored per sample. Figure 1 shows sample metaphase spreads with and without chromatid breaks.

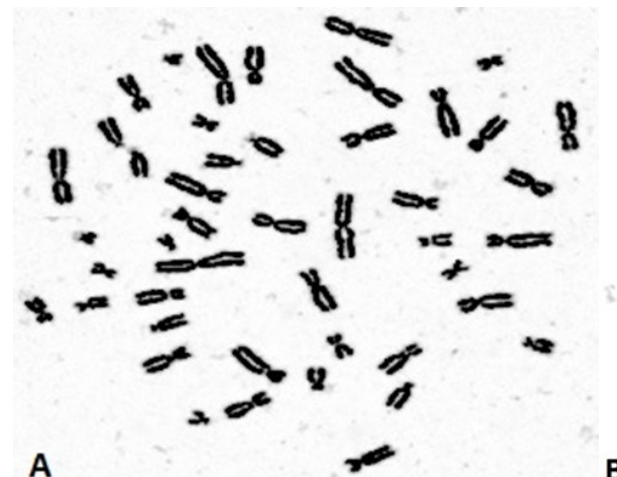

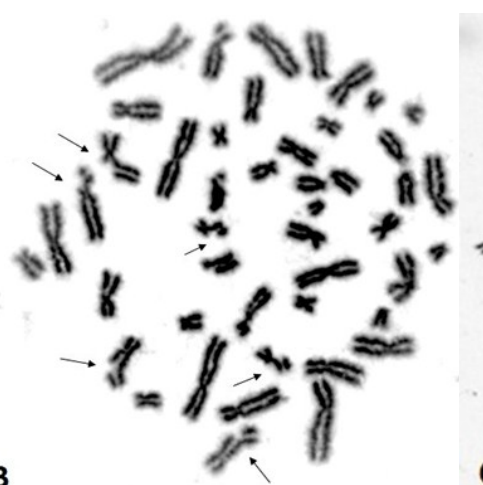

C

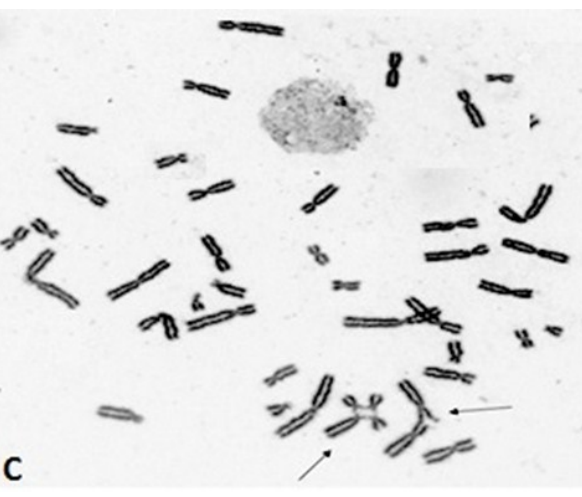

(1) metaphase with rare exchange aberrations (triradial and quadriaradial, arrows). Magnification $\times 1000$.

\section{Statistical analysis}

SPSS (version 18, Chicago, IL, USA) was used to do statistical analysis on data obtained. Non- parametric Mann-Whitney U-test one way analysis of variance (ANOVA) was used to test the significant difference between studied groups. P-value less than 0.05 was regarded as significant level.

\section{RESULTS}

The data obtained from normal control and breast cancer patients before and after 1Gy gamma irradiation with and without melatonin is summarized in table 1 and shown in figures 2 and 3.

\section{Results of patients}

As seen in figure 3, the effect of melatonin alone was more pronounced compared to background frequency of chromatid breaks in lymphocytes of patients statistically significant $(p<0.05)$. The frequency of radiation induced chromatid breaks was significantly higher than control $(p<0.01)$. Moreover, pretreatment of lymphocytes with melatonin led to an increased in frequency of radiation induced aberration $(\mathrm{p}<0.01)$.

Table 1. Mean frequency of chromatid breaks scored in blood samples obtained from control individuals and breast cancer patients. SD indicates standard deviation of mean values.

\begin{tabular}{|l|c|c|c|c|c|c|c|}
\hline Subjects & $\begin{array}{c}\text { No. of } \\
\text { samples }\end{array}$ & $\begin{array}{c}\text { Mean } \\
\pm \text { SD age } \\
\text { (Range) }\end{array}$ & $\begin{array}{c}\text { No. of } \\
\text { cells } \\
\text { analyzed }\end{array}$ & $\begin{array}{c}\text { Mean } \pm \text { SD } \\
\text { background } \\
\text { breaks }\end{array}$ & $\begin{array}{c}\text { Mean } \pm \text { SD } \\
\text { break induced } \\
\text { Melatonin alone }\end{array}$ & $\begin{array}{c}\text { Mean } \pm \text { SD } \\
\text { gamma rays } \\
\text { induced breaks }\end{array}$ & $\begin{array}{c}\text { Mean } \pm \text { SD gamma } \\
\text { rays induced breaks in } \\
\text { presence of melatonin }\end{array}$ \\
\hline Control & 5 & $\begin{array}{c}37.4 \pm 11 \\
(23-66)\end{array}$ & 500 & $1.4 \pm 1.02$ & $2.14 \pm 1.06$ & $14.0 \pm 9.14$ & $15.2 \pm 6.05$ \\
\hline $\begin{array}{c}\text { Breast } \\
\text { cancer } \\
\text { patient }\end{array}$ & 10 & $\begin{array}{c}46 \pm 13.9 \\
(25-76)\end{array}$ & 1000 & $5.6 \pm 3.4$ & $15.1 \pm 22.23$ & $72.1 \pm 27.85$ & $119 \pm 46.67$ \\
\hline
\end{tabular}




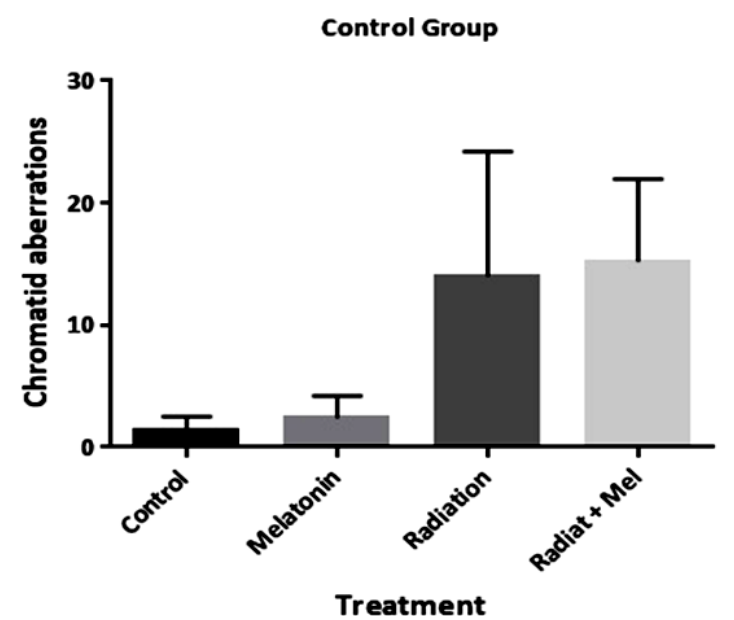

Figure 2. Frequency of chromatid aberrations observed in lymphocytes of normal controls. Error bars Indicate standard deviation of mean values.

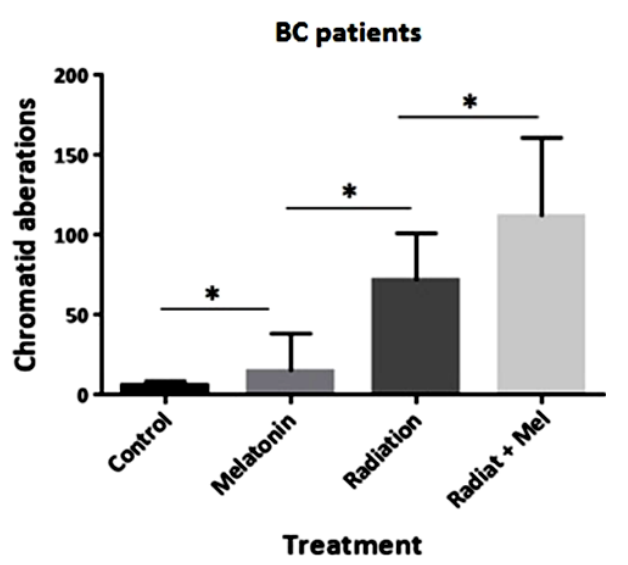

Figure 3. Frequency of chromatid aberrations observed in lymphocytes of BC patients. Error bars Indicate standard deviation of mean values.

\section{DISCUSSION}

The $\mathrm{G}_{2}$ chromosomal aberration assay is a well-accepted method to study interaction of radiation and chemical agents. Result of the study presented in table 1 and figures 2 and 3 indicate that lymphocytes of breast cancer patients received melatonin $3 \mathrm{~h}$ before irradiation show an elevated frequency of chromatid aberration compared to cells received radiation alone; suggesting that the addition of melatonin promotes chromatid breaks and enhances the effects of radiation.

Useful properties of melatonin in the prevention and treatment of breast cancer were reviewed in Mediavilla et al. (22). These properties include antioxidant effects (23), regulation of the estrogen receptor expression (24), regulation of the enzymes involved in the synthesis of estrogens (25-27), modulation of cell cycle and apoptosis (28) as well as inhibition of telomerase activity (29). Moreover it was shown that melatonin stimulates cell differentiation (30), prevents angiogenesis (31), inhibits metastasis (32), prevents circadian disruption (33), and reduces epigenetic effects $(34,35)$. Melatonin by its antioxidant properties reduces the side effects of radiotherapy (15) by scavenging ROS and reactive nitrogen species (16). Moreover, melatonin triggers the expression of antioxidant enzyme (17) and reduces the expression of pro-oxidative enzymes (18). Although melatonin was previously considered as an antioxidant agent, particularly as scavenger of ROS, our results demonstrate that melatonin could act as a radiosensitizer. Similar results with slight variations were reported previously. Alonso -Gonzalez (19) reported melatonin pretreatment before radiation sensitizes breast cancer cells to the ionizing effects of radiation by downregulation proteins (RAD51, DNA-PKcs) involved in double -strand DNA break repair. It has been shown that melatonin can also reduce the effectiveness of DNA repair and increase the rate of DNA damage promoted by irinotecan, a camptothecin analog used in clinic for treatment of different malignancies, in human non-small-cell lung cancer and human colorectal adenocarcinoma cell lines (36). As well as, melatonin by decreasing the ratio of cells in the $S$ and G2 phases decrease the probability to repair the DNA damage by homologous recombination, which occur in these phases of the cell cycle in breast cancer (37). However, the accurate roles of p53 in repair of DSBs stand controversial, there are evidences for a straight role of p53 in homologues recombination as well as in nonhomologous DNA end joining $(37,38)$. Melatonin augments the expression of P21WAF1 and p53 (39), two regulatory proteins of the cell cycle, in $\mathrm{BC}$ cell, and this mode of action of melatonin could be related to its modulatory effect on DNA repair.

In addition to the antioxidant mechanisms of melatonin and protection of DNA, our results show that melatonin influence on the 
radio-sensitivity of lymphocytes of breast cancer patients. Free radical scavenging activity of melatonin has been reported previously ${ }^{(40)}$.

In conclusion results of the present study indicate that despite antioxidant property of melatonin, treatment of cells with melatonin before irradiation led to an increased clastogenic effect in lymphocytes of BC patients. The mechanism by which melatonin enhanced radiation effect is not fully understood but may be due to alterations in genes involved in DNA repair process leading to increased chromatid aberration.

\section{ACKNOWLEDGEMENTS:}

Authors express their sincere gratitude's to all patients and healthy individuals for their volunteer contribution to the work and blood donation. We also thank Mr. Hassan Nosrati for irradiation of samples and to the staff of the Cytogenome Medical Genetics lab especially, Miss Sahar Mozdarani for her technical assistance.

\section{Conflicts of interest: Declared none.}

\section{REFERENCES}

1. Torres-Roca JF and Stevens CW (2008) Predicting response to clinical radiotherapy: past, present, and future directions. Cancer Control, 15(2): 151-6.

2. $P D Q{ }^{\circledR}$ Screening and Prevention Editorial Board (2017). PDQ Breast Cancer Prevention; National Cancer Institute: Bethesda, MD, USA. Available online: https.// www.cancer.gov/types/breast/hp/breast-prevention (accessed on 20 December 2017).

3. Nosrati H, Mozdarani H, Hadad P, Omranipour R (2017) Inherent radiation sensitivity of lymphocytes of triple negative (TN) and luminal $A$. A comparison between patients with breast cancer and normal individuals as assayed by the micronucleus test. Arch Breast Cancer, 4(1): 10-15.

4. Yorke ED, JacksonA, Rosenzweig KE, Merrick SA, Gabrys D, Venkatraman ES, et al. (2002) Dosevolume factors contributing to the incidence of radiation pneumonitis in nonsmall-cell lung cancer patients with three-dimensional conformal radiation therapy. Int J Radiat Oncol Biol Phys, 54(2): 329-39.

5. Dreher D and Junod AF (1996) Role of oxygen free radicals in cancer development. Eur J Cancer, 32A: 30-8.

6. Block KI, Koch AC, Mead MN, et al. (2008) Impact of antioxidant supplementation on chemotherapeutic toxicity:a systematic review of the evidence from randomized controlled trials. Int J Cancer, 123: 1227-39.

7. Karbownik M, Lewinski A, Reiter RJ (2001) Anticarcinogenic actions of melatonin which involve antioxidative processes: comparison with other antioxidants. Int J Biochem Cell Biol, 33: 735-53.

8. Mediavilla MD, Sanchez-Barcelo EJ, Tan DX, et al. (2010) Basic mechanisms involved in the anti-cancer effects of melatonin. Curr Med Chem, 17: 4462-81.

9. Subramanian A and Kothari L (1991) Suppressive effect by melatonin on different phases of 9, 10-dimethyl- 1, 2- benzanthracene (DMBA)-induced rat mammary gland carcinogenesis. Anticancer Drugs, 2: 297-303.

10. Cos S and Sánchez-Barceló, EJ (2000) Melatonin, experimental basis for a possible application in breast cancer prevention and treatment. Histol Histopathol, 15: 637647.

11. Cos S and Sánchez-Barceló EJ (2000) Melatonin and mammary pathological growth. Neuroendocrinol, 21: 133-170.

12. Sánchez-Barceló EJ, Cos S, Fernández R, Mediavilla MD (2003) Melatonin and mammary cancer: A short review; Endocr Relat Cancer, 10: 153-159.

13. Oz E, Erbas D, Surucu HS, et al. (2006) Prevention of doxorubicin-induced cardiotoxicity by melatonin. Mol Cell Biochem, 282: 31-7.

14. Reiter RJ, Tan DX, Korkmaz A, et al. (2007) Light at night, chronodisruption, melatonin suppression, and cancer risk: a review. Crit Rev Oncog, 13: 303-28.

15. Sanchez-Barcelo EJ, Mediavilla MD, Alonso-Gonzalez C, Reiter RJ (2012) Melatonin uses in oncology: Breast cancer prevention and reduction of the side effects of chemotherapy and radiation. Expert Opin Inv Drug, 21: 819-831.

16. Galano A, Tan DX, Reiter RJ (2011) Melatonin as a natural ally against oxidative stress: a physicochemical examination. J Pineal Res, 51: 1-16.

17. Rodriguez C, Mayo JC, Sainz RM, et al. (2004) Regulation of antioxidant enzymes: a significant role for melatonin. $J$ Pineal Res, 36: 11-19.

18. Pozo D, Reiter RJ, Calvo JR, et al. (1997) Inhibition of cerebellar nitric oxide synthase and cyclic GMP production by melatonin via complex formation with calmodulin. J Cell Biochem, 65: 430-42.

19. Alonso-Gonzalez C, Gonzalez A, Martinez-Campa C, GomezArozamena J, Cos S (2015) Melatonin sensitizes human breast cancer cells to ionizing radiation by downregulating proteins involved in double-strand DNA break repair. J Pineal Res, 58: 189-197.

20. Vijayalaxmi, Reiter RJ, Meltz ML, Herman TS (1998) Melatonin: possible mechanisms involved in its 'radioprotective' effect. Mutat Res, 404(1-2): 187-9.

21. Vijayalaxmi Meltz ML, Herman TS (1999) Melatonin and protection from genetic damage in blood and bone marrow: Whole-body irradiation studies in mice. J Pineal Res, 27 (4); 221-225. 
22. Mediavilla MD, S_Anchez-Barcel_O EJ, TAN DX et al. (2010) Basic mechanisms involved in the anticancer effects of melatonin. Curr Med Chem, 17: 4462-4481.

23. Karbownik M, Lewinski A, Reiter RJ (2001) Anticarcinogenic actions of melatonin which involve antioxidative processes: comparison with other antioxidants. Int J Biochem Cell Biol, 33: 735-753.

24. Kiefer T, Ram Pt, Yuan L et al. (2002) Melatonin inhibits estrogen receptor transactivation and CAMP levels in breast cancer cells. Breast Cancer Res Treat, 71: 37-45.

25. Cos S, Gonz_Alez A, Mart_Inez-Campa C, et al. (2006) Estrogen-signaling pathway: a link between breast cancer and melatonin oncostatic actions. Cancer Detect Prev, 30: 118-128.

26. Cos S, Gonz_Alez A, Mart_Inez-Campa C, et al. (2008) Melatonin as a selective estrogen enzyme modulator. Curr Cancer Drug Targets, 8: 691-702.

27. Gonz_Alez A, Cos S, Martinez-Campa C et al. (2008) Selective estrogen enzyme modulator (SEEM) actions of melatonin in human breast cancer cells. J Pineal Res, 45: 8692.

28. Cos S, Blask De, Lemus-Wilson A, et al. (1991) Effects of melatonin on the cell cycle kinetics and "estrogen rescue" of MCF-7 human breast cancer cells in culture. J Pineal Res, 10: 36-42.

29. Leon-Blanco M, Guerrero Jm, Reiter Rj, et al. (2003) Melatonin inhibits telomerase activity in the MCF-7 tumor cell line in-vivo and in-vitro. J Pineal Res, 35: 204-211.

30. Miller Sc, Pandi-Perumal Sr, Esquifino Ai, et al. (2006) The role of melatonin in immuno-enhancement: potential application in cancer. Int J Exp Pathol, 87: 81-87.

31. Park SY, Jang WJ, Yi EY, et al. (2010) Melatonin suppresses tumor angiogenesis by inhibiting HIF-1a stabilization under hypoxia. J Pineal Res, 48: 178-184.

32. Cos S, Fern_Andez R, G€Uezmes A, et al. (1998) Influence of melatonin on invasive and metastatic properties of MCF -7 human breast cancer cells. Cancer Res, 58: 4383-4390.

33. Blask De, Brainard Gc, Dauchy Rt, et al. (2005) Melatonindepleted blood from premenopausal women exposed to light at night stimulates growth of breast cancer xenografts in nude rats. Cancer Res, 65: 11174-11184.

34. Proietti S, Cucina A, Dobrowolny G, et al. (2014) Melatonin down-regulates MDM2 gene expression and enhances p53 acetylation in MCF-7 cells. J Pineal Res, 57: 120-129.

35. Lee Se, Kim Sj, Yoon Hj, et al. (2013) Genome-wide profiling in melatonin-exposed human breast cancer cell lines identifies differentially methylated genes involved in the anticancer effect of melatonin. J Pineal Res, 54: 80-88.

36. Kontek R and Nowicka H (2013) The modulatory effect of melatonin on genotoxicity of irinotecan in healthy human lymphocytes and cancer cells. Drug Chem Toxicol, 36: 335 -342 .

37. Mao Z, Jiang $Y$, Liu X, et al. (2009) DNA repair by homologous recombination, but not by nonhomologous end joining, is elevated in breast cancer cells. Neoplasia, 11: 683691.

38. Goodarzi Aa and Jeggo Pa (2013) The repair and signaling responses to DNA double-strand breaks. Adv Genet, 82: 145.

39. Gatz SA and Wiesmüller L (2006) p53 in recombination and repair. Cell Death Differ, 13: 1003-1016.

40. Mediavilla MD, Cos S, Sánchez-Barceló EJ (1999) Melatonin increases p53 and p21WAF1 expression in MCF-7 human breast cancer cells in-vitro. Life Sci, 65: 415-420. 